\section{(6) OPEN ACCESS}

\title{
A randomised phase Ilb study of mavrilimumab, a novel GM-CSF receptor alpha monoclonal antibody, in the treatment of rheumatoid arthritis
}

\author{
Gerd R Burmester, ${ }^{1}$ lain B Mclnnes, ${ }^{2}$ Joel Kremer, ${ }^{3}$ Pedro Miranda, ${ }^{4}$ \\ Mariusz Korkosz, ${ }^{5}$ Jiri Vencovsky, ${ }^{6}$ Andrea Rubbert-Roth, ${ }^{7}$ Eduardo Mysler, ${ }^{8}$ \\ Matthew A Sleeman, ${ }^{9}$ Alex Godwood, ${ }^{9}$ Dominic Sinibaldi, ${ }^{10}$ Xiang Guo, ${ }^{10}$ \\ Wendy I White, ${ }^{10}$ Bing Wang, ${ }^{11}$ Chi-Yuan Wu, ${ }^{11}$ Patricia C Ryan, ${ }^{10}$ David Close, ${ }^{9}$ \\ Michael E Weinblatt, ${ }^{12}$ on behalf of the EARTH EXPLORER 1 study investigators
}

\begin{abstract}
Handling editor Tore K Kvien
- Additional material is published online only. To view please visit the journal online (http://dx.doi.org/10.1136/ annrheumdis-2016-210624)

For numbered affiliations see end of article.
\end{abstract}

\section{Correspondence to}

Dr Gerd R Burmester, Director, Department of Rheumatology and Clinical Immunology, Charité-University Medicine Berlin, Free University, and Humboldt University Berlin Charitéplatz 1, Berlin 10117 Germany; Gerd.Burmester@ charite.de

GRB and IBM contributed equally.

DC and MEW are joint senior authors.

Received 30 September 2016 Revised 9 December 2016 Accepted 16 January 2017 Published Online First 16 February 2017

\section{ABSTRACT}

Objectives Despite the therapeutic value of current rheumatoid arthritis (RA) treatments, agents with alternative modes of action are required. Mavrilimumab, a fully human monoclonal antibody targeting the granulocyte-macrophage colony-stimulating factor receptor- $\alpha$, was evaluated in patients with moderate-tosevere RA.

Methods In a phase IIb study (NCT01706926), patients with inadequate response to $\geq 1$ synthetic disease-modifying antirheumatic drug(s), Disease Activity Score 28 (DAS28)-C reactive protein (CRP)/erythrocyte sedimentation rate $\geq 3.2, \geq 4$ swollen joints despite methotrexate (MTX) were randomised 1:1:1:1 to subcutaneous mavrilimumab $(150,100,30 \mathrm{mg})$, or placebo every other week (eow), plus MTX for 24 weeks. Coprimary outcomes were DAS28-CRP change from baseline to week 12 and American College of Rheumatology (ACR) 20 response rate (week 24).

Results 326 patients were randomised $(150 \mathrm{mg}, \mathrm{n}=79$; $100 \mathrm{mg}, \mathrm{n}=85 ; 30 \mathrm{mg}, \mathrm{n}=81$; placebo, $\mathrm{n}=81) ; 305$ completed the study (September 2012-June 2013). Mavrilimumab treatment significantly reduced DAS28 -CRP scores from baseline compared with placebo (change from baseline (SE); $150 \mathrm{mg}:-1.90(0.14)$, $100 \mathrm{mg}:-1.64$ (0.13), $30 \mathrm{mg}:-1.37$ (0.14), placebo: $-0.68(0.14) ; p<0.001$; all dosages compared with placebo).

Significantly more mavrilimumab-treated patients achieved ACR20 compared with placebo (week 24: $73.4 \%, 61.2 \%, 50.6 \%$ vs $24.7 \%$, respectively $(p<0.001))$. Adverse events were reported in 43 $(54.4 \%), 36(42.4 \%), 41(50.6 \%)$ and $38(46.9 \%)$ patients in the mavrilimumab 150,100, $30 \mathrm{mg}$ eow and placebo groups, respectively. No treatment-related safety signals were identified.

Conclusions Mavrilimumab significantly decreased RA disease activity, with clinically meaningful responses observed 1 week after treatment initiation, representing a novel mechanism of action with persuasive therapeutic potential.

Trial registration number NCT01706926; results.

\section{INTRODUCTION}

Biological therapies have improved disease control and patient outcomes in rheumatoid arthritis (RA).
However, approximately 50\% of patients do not achieve low disease activity criteria within 12 months of antitumour necrosis factor- $\alpha$ treatment, ${ }^{1}$ while approximately $80 \%$ of patients do not achieve Disease Activity Score 28 (DAS28) -erythrocyte sedimentation rate $(\mathrm{ESR})<2.6^{2}$ It is possible that biologics targeting novel signalling pathways may prove beneficial in RA, including in these patients.

Recently, granulocyte-macrophage colonystimulating factor (GM-CSF), a proinflammatory multifunctional cytokine, has emerged as a novel and important therapeutic target in autoimmune/ inflammatory diseases. ${ }^{3}$ In RA pathogenesis, GM -CSF plays a key role through activation, differentiation and survival of macrophages, dendritic cells and neutrophils. ${ }^{4-6}$ In addition, GM-CSF is now well recognised as an effector $\mathrm{T}$ helper $1 / 17$ cell cytokine. $^{3} 7$ Elevated concentrations of GM-CSF and its receptor have been observed in tissue and synovial fluid of patients with $\mathrm{RA},{ }^{8-10}$ and recombinant GM-CSF administration exacerbates RA disease activity. ${ }^{11}$ Moreover, signalling through the GM-CSF receptor- $\alpha$ subunit (GM-CSFR- $\alpha$ ) has been shown to have a role in animal models of arthritis $^{10}{ }^{12}$ and modulation of pain pathways. ${ }^{13}$ Inhibition of the GM-CSF pathway reduces macrophage and/or neutrophil numbers in inflammatory lesions. ${ }^{14}$ This treatment approach may hold promise in RA and other diseases characterised by the activation of the monocyte-macrophage pathway. In humans, full inhibition of GM-CSF signalling, via emergence of GM-CSF neutralising polyclonal autoantibodies, has been associated with the development of foamy alveolar macrophages, and, clinically, with a lung disorder, pulmonary alveolar proteinosis (PAP). ${ }^{15}$

Mavrilimumab, a fully human monoclonal antibody which blocks the GM-CSF receptor, is the first biologic in clinical development to target this pathway. Clinical studies demonstrated the pharmacokinetics, pharmacodynamics and safety/tolerability of mavrilimumab, and provided evidence of efficacy. ${ }^{16-20}$ In this longer 24-week phase IIb study, we evaluated the therapeutic potential of GM-CSF antagonism in patients with moderate-to-severe, adult-onset RA by comparing the efficacy and 
safety/tolerability of subcutaneous mavrilimumab, at dosages of up to $150 \mathrm{mg}$ every other week (eow) plus methotrexate (MTX), with that of placebo.

\section{METHODS}

\section{Study design}

This phase IIb, randomised, double-blind, parallel-group, placebo-controlled study (EARTH EXPLORER 1; NCT01706926) was conducted in 48 specialist sites (14 countries; Europe, South America, South Africa) (see online supplementary table S1). Population pharmacokinetic efficacy modelling and stochastic clinical trial simulations facilitated selection of the optimal dose range for the study.

Due to the theoretical risk associated with GM-CSF inhibition and data from non-clinical (animal toxicology) studies of mavrilimumab, ${ }^{21}$ standardised pulmonary monitoring with independent expert adjudication was undertaken. ${ }^{22}$

The study was conducted in accordance with the principles of the Declaration of Helsinki and the International Conference on Harmonisation Guidance for Good Clinical Practice and approved by appropriate institutional review boards or independent ethics committees at each site.

\section{Patients}

Patients were $18-80$ years with moderate-to-severe, adult-onset $\mathrm{RA}^{23}$ DAS28-C reactive protein (CRP) $\geq 3.2$ at screening and DAS28-ESR $\geq 3.2$ at day $1,{ }^{24}$ and $\geq 4$ swollen joints at screening and day 1 , and were receiving stable dosages of MTX $(7.5-25.0 \mathrm{mg} /$ week). Patients were required to have received treatment with $\geq 1$ traditional disease-modifying antirheumatic drug (DMARD) prior to screening. Previous treatment with any biological DMARD discontinued because of lack of efficacy; recent treatment with any investigational drug, alkylating agents or parenteral steroids; and concurrent treatment with DMARDs other than MTX were not permitted. Changes in background RA treatment were not allowed for the first 12 weeks of the study, other than for safety reasons. Patients with clinically uncontrolled respiratory disease, active infection or high infection risk, and active or untreated latent tuberculosis were excluded. All patients provided written informed consent and were enrolled by the investigator or qualified designee. Study-stopping criteria are listed in the online supplementary material.

\section{Randomisation and masking}

Patients were randomised (interactive web response system) $1: 1: 1: 1$ to 150,100 or $30 \mathrm{mg}$ subcutaneous mavrilimumab or placebo eow in combination with stable dosages of MTX (7.5$25.0 \mathrm{mg} /$ week) for 24 weeks, followed by transfer to a longterm, open-label extension (OLE) (NCT01712399) or a 12 -week safety follow-up period. Study patients, investigators and sponsors were blinded to study treatment (see online supplementary material).

\section{Procedures}

During the 24-week treatment period, there were 14 scheduled visits (weeks 0,1, 2 and eow until week 24). The safety follow-up period included visits at 4,8 and 12 weeks after the last dose. Twelve weeks after treatment initiation, patients without adequate response $(<20 \%$ improvement in both swollen and tender joint counts vs day 1 ) were eligible for early OLE entry. Corticosteroids $(\leq 7.5 \mathrm{mg} /$ day prednisolone or equivalent), analgesics and non-steroidal anti-inflammatory drugs were maintained at stable dosages for the study duration.

\section{End points}

\section{Primary end points}

Coprimary end points were change from baseline in DAS28 -CRP score (week 12) and American College of Rheumatology (ACR) 20 (20\% improvement in ACR criteria) response (week 24). Assessments performed are included in the online supplementary material.

\section{Secondary end points}

Secondary efficacy end points included: DAS28-CRP European League Against Rheumatism (EULAR) response rates, DAS28 -CRP-defined remission $(<2.6)$ and low disease activity $(<3.2)$, ACR20/50/70 response rates at weeks 12 and 24, change from baseline or geometric means for ACR and DAS28 components over time and DAS28-ESR response. Assessments were performed at weeks $0,1,2,4,8,12,16,20$ and 24 .

CRP and ESR geometric means were measured over time.

\section{Exploratory end points}

Exploratory end points, including disease activity and structural damage biomarkers, were examined at weeks 0, 1, 2, 4, 12 and 24. Multibiomarker disease activity (MBDA) Vectra DA score (Crescendo Biosciences, South San Francisco, California, USA) ${ }^{25}$ was calculated to track the effects of mavrilimumab on inflammatory biomarkers at predefined time points.

An ELISA was used to measure serum concentrations of $\mathrm{C} 1 \mathrm{M},{ }^{26}$ a marker of tissue damage associated with structural progression. $^{27}$

\section{Safety assessments}

Adverse events (AEs) and serious adverse events (SAEs) were summarised by severity and relationship to study drug by investigators. Laboratory evaluations (serum chemistry, haematology, urinalysis), vital signs, pulmonary function tests (PFTs), dyspnoea score and oxygen saturation were summarised by treatment group and time point. Serum was tested for antidrug antibodies (ADAs) and mavrilimumab concentrations throughout the study. Safety assessments were performed at every visit during the treatment period.

PFTs (forced vital capacity, forced expiratory volume in 1 and $6 \mathrm{~s})$ were performed at screening, and at weeks 12 and 24. Dyspnoea score and oxygen saturation were assessed at each visit using the modified Borg scale and pulse oximetry, respectively. Adjudication of lung function abnormalities and pulmonary AEs was by an Independent Pulmonary Expert Committee.

\section{Statistical analysis}

The primary efficacy population was the modified intention-to-treat population (all randomised patients who received any study drug). The safety population included all patients who received study drug and had safety data available.

A sample size of 70 patients per treatment group provided $80 \%$ power to achieve statistical significance for DAS28-CRP and ACR20 at a two-sided significance level of 0.05 . This assumed a 0.6-unit difference in change from baseline and a SD of 1.25 for DAS28-CRP, and a 25\% difference in ACR20 response rate with a placebo response rate of $40 \%$.

Change from baseline in DAS28-CRP was analysed using a mixed model for repeated measures (MMRM), with covariates for baseline DAS28-CRP, visit, treatment and visit-by-treatment interaction. Dosage-response assessment was performed using a test for linear trend on DAS28-CRP change from baseline at week 12 . Two sensitivity analyses were performed for change 
from baseline DAS28-CRP to allow for patients withdrawing from treatment (see online supplementary material). ACR20/50/ 70 response rates, DAS28-defined remission $(<2.6)$ and response rates at each visit were analysed using logistic regression, with results presented as differences in response rates (95\% CI; p value). ${ }^{28}$ Individual ACR components were analysed using the same method as for DAS28-CRP analyses.

DAS28-CRP EULAR responses at each time point were analysed via a proportional odds model, with treatment as a factor. CRP and ESR were log-transformed prior to analysis. For discrete responder outcomes, patients who withdrew from treatment for any reason (including entering the OLE), started any new RA medication, or increased MTX dosage, were imputed as non-responders for all subsequent assessments. For continuous outcomes (DAS28-CRP and ACR components), missing data were handled by the MMRM analysis (including patients entering the OLE). For MBDA and C1M, results for each time point were analysed versus placebo using a non-parametric Mann-Whitney $U$ test. AE and other safety data were summarised with descriptive statistics. An external independent safety data monitoring board oversaw the study.

\section{RESULTS}

Patients were recruited between September 2012 and June 2013, with evaluation until January 2014. Of 326 patients randomised, 305 (93.6\%) completed the study. Patient disposition is presented in figure 1. Demographics and baseline clinical characteristics were similar between treatment groups, and indicated a cohort of patients with predominantly severe disease (DAS28-CRP > 5.1) that would qualify for first-line biological therapy (see table 1 and online supplementary table S2).

Mavrilimumab significantly reduced DAS28-CRP scores from baseline compared with placebo at week 12, meeting the coprimary outcome (change from baseline (difference from placebo (95\% CI)) $150 \mathrm{mg}$ : $-1.90(-1.22(-1.60$ to -0.84$))$, $100 \mathrm{mg}:-1.64(-0.96(-1.33$ to -0.58$)), 30 \mathrm{mg}:-1.37(-0.69$ $(-1.06$ to -0.31$)$ ), placebo: $-0.68 ; \mathrm{p}<0.001$, all dosages; figure 2A). Differences from placebo were detected at week 1 , with treatment benefit increasing through week 12 (figure 2A). At week 24, significantly more patients receiving mavrilimumab $150 \mathrm{mg}$ eow achieved an ACR20 response compared with placebo, with a dosage-dependent response $(150 \mathrm{mg}$ : $73.4 \%$; $100 \mathrm{mg}$ : 61.2\%; $30 \mathrm{mg}$ : 50.6\%; placebo: 24.7\% ( $<<0.001)$; figure $2 \mathrm{~B}$ ), indicating that the study also met its second coprimary outcome. There were significantly more ACR20 responders in the mavrilimumab $150 \mathrm{mg}$ eow group than in the placebo group from the first assessment (week 1) and at every other assessment through to week 24 (figure 2B). Subgroup analyses of ACR2 0 by CRP concentration (normal or greater than the upper limit of normal), the presence of rheumatoid factor and/ or anticitrullinated protein antibody (ACPA), and prior use of biologics and smoking status (see online supplementary table S3) suggest that clinical response is not dependent on baseline disease characteristics. Furthermore, mavrilimumab was demonstrated to be efficacious in patients who were rheumatoid factor negative and ACPA-negative at baseline $(n=59 ; 18.1 \%)$.

DAS28-CRP/ESR EULAR good and moderate responses occurred more frequently with mavrilimumab 150, 100 and $30 \mathrm{mg}$ eow than placebo at weeks 12 and 24 (figure 3). This was also true for ACR20 and ACR50 response rates (ACR50 response at week 24: 40.5\%, 25.9\%, 28.4\% and $12.3 \%$, respectively; $\mathrm{p}<0.05$, all dosages; figure 3). Mavrilimumab $150 \mathrm{mg}$ eow significantly improved ACR70 response rates compared with placebo at weeks 12 and 24 (week 12: 10.1\% vs $1.2 \% \quad(p=0.017)$; week $24: 13.9 \%$ vs $3.7 \% \quad(p=0.026)$; figure 3 ). At week 24, there was a significantly greater ACRn response for patients receiving mavrilimumab compared with placebo (figure 3). Rates of DAS28-CRP remission $(<2.6)$ were also significantly greater with mavrilimumab $150 \mathrm{mg}$ compared with placebo at week 12 and all dosages of mavrilimumab compared with placebo at week $24(\mathrm{p}<0.05$, all dosages; figure 3$)$. There were significantly more patients with DAS28-CRP low disease activity scores $(<3.2)$ in the mavrilimumab $150 \mathrm{mg}$ eow group compared with placebo at weeks 12, 16, 20, 24 (31.6\%, $40.5 \%, 43.0 \%, 41.8 \%$ vs $12.3 \%, 14.8 \%, 14.8 \%, 8.6 \%$, respectively) and in all mavrilimumab groups compared with placebo at week $24(p<0.001$; figure 3$)$. To confirm the robustness of the data, analyses of change from baseline in DAS28-ESR were also performed, and results were similar to those using DAS28 -CRP (see online supplementary figure S1).

Results for components of composite outcomes were similar. Greater changes from baseline in ACR and DAS28 components, and patient-reported outcomes compared with placebo were observed at weeks 12 and 24 for patients receiving mavrilimumab $150 \mathrm{mg}$ eow (see online supplementary table S4). As a greater number of patients in the placebo group than in the mavrilimumab group transferred to the OLE study between weeks 12 and 24 because of lack of response under 'rescue' criteria, it is important to interpret the week 24 data with caution.

A dosage-dependent, rapid (week 1) and sustained (week 24) reduction of both CRP and ESR concentrations was also observed, with CRP levels plateauing at approximately $3.3 \mathrm{mg} / \mathrm{L}$ (see figure 4A and online supplementary figure S2, respectively).

Of 326 patients, 120 reported at least one AE (150 mg: 43 (54.4\%); $100 \mathrm{mg}$ : 36 (42.4\%); $30 \mathrm{mg}$ : 41 (50.6\%); placebo: 38 $(46.9 \%))$. The most common treatment-emergent AEs (TEAEs), and those leading to discontinuation or interruption of the study drug, are provided in table 2 . SAEs were reported for two $(2.5 \%)$, five $(5.9 \%)$, four $(4.9 \%)$ and one $(1.2 \%)$ patients in the mavrilimumab $150,100,30 \mathrm{mg}$ eow and placebo groups, respectively (table 2). Of these, only pneumonia (mavrilimumab $30 \mathrm{mg}$ eow) and angioedema (mavrilimumab $150 \mathrm{mg}$ eow) were considered to be related to treatment by the investigator.

Rates of pulmonary AEs for mavrilimumab 150,100 or $30 \mathrm{mg}$ eow were similar to the rate for placebo $(6.3 \%, 3.5 \%, 6.2 \%$ vs $9.9 \%$, respectively). There were no deaths or anaphylaxis. Two hypersensitivity AEs led to discontinuation (angioedema 6 days after first dose, mavrilimumab $150 \mathrm{mg}$ eow; drug hypersensitivity 1 day after first dose, mavrilimumab $30 \mathrm{mg}$ eow).

No clinically meaningful differences between mavrilimumabtreated and placebo-treated patients in haematology, including neutrophils, serum chemistry and urinalysis parameters, were observed. ADAs were detected in 0 (0.0\%), $3(3.5 \%), 13$ $(16.0 \%)$ and $2(2.5 \%)$ patients in the mavrilimumab 150, 100, $30 \mathrm{mg}$ eow and placebo groups, respectively (see online supplementary material). One injection-site reaction was observed (mavrilimumab $150 \mathrm{mg}$ eow).

Pulmonary function values, dyspnoea scores and oxygen saturation were generally similar between mavrilimumab-treated and placebo-treated patients, with no evidence of a dosagedependent decline in the mean values for patients receiving mavrilimumab (see online supplementary table S5). Any threshold changes in the percentage of PFT values were generally transient.

In biomarker analyses, treatment with mavrilimumab 150 and $100 \mathrm{mg}$ eow induced early (week 1) and sustained (week 24) significant reductions in MBDA score versus placebo $(p<0.01$; 


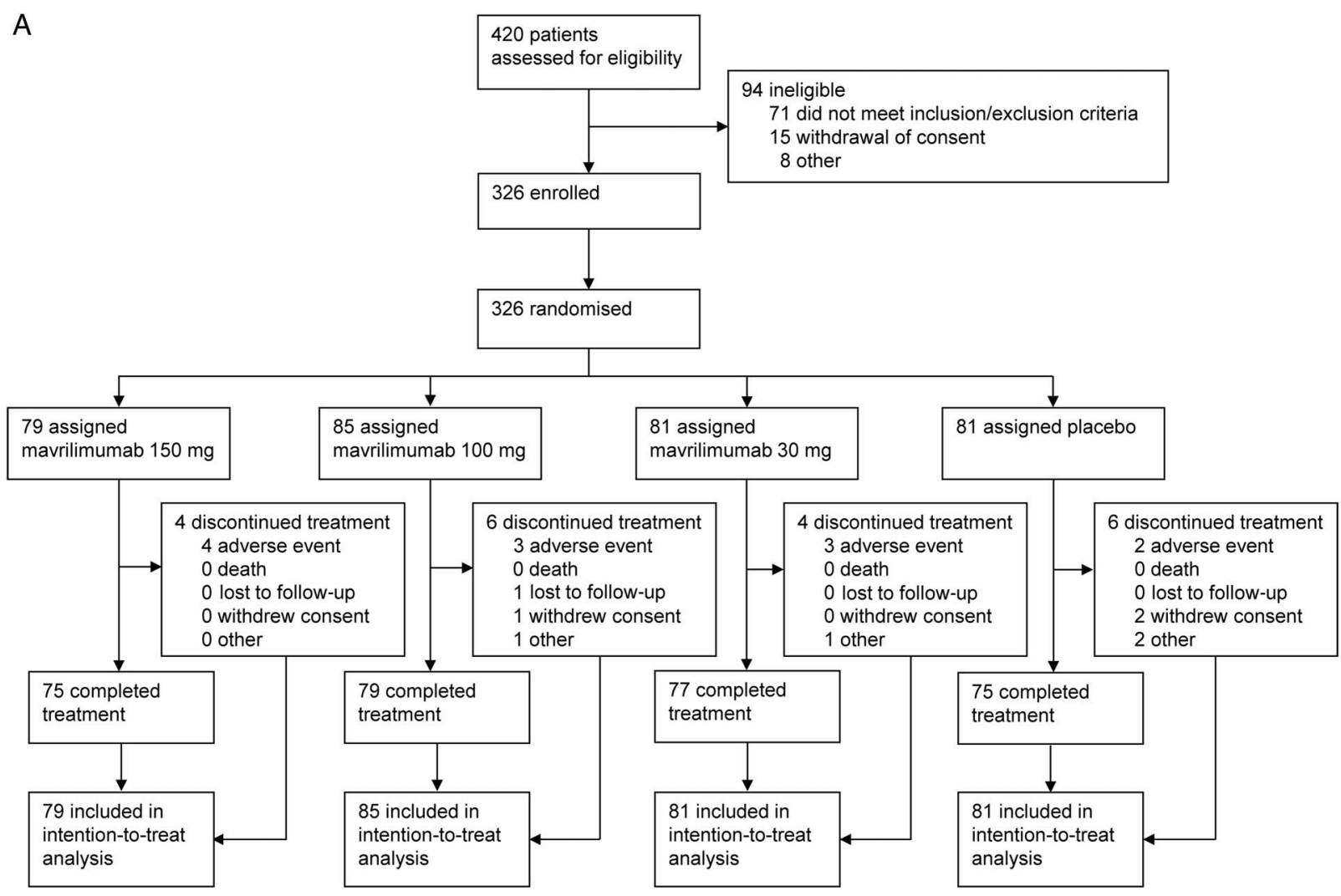

B

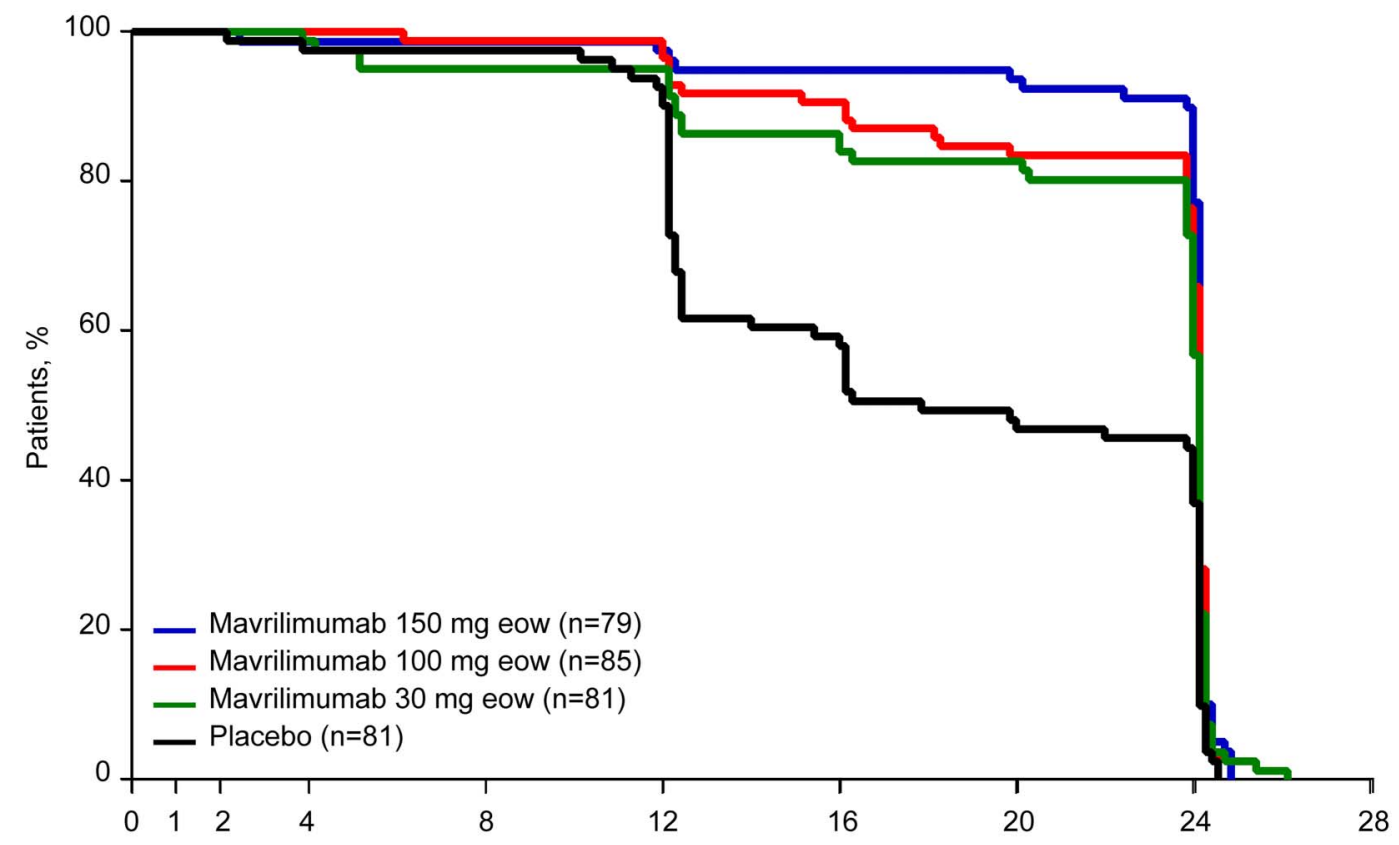

Time (weeks)

Number at risk

\begin{tabular}{|c|c|c|c|c|c|c|c|}
\hline Mavrilimumab $150 \mathrm{mg}$ & 797979 & 78 & 78 & 77 & 75 & 74 & 61 \\
\hline Mavrilimumab $100 \mathrm{mg}$ & 858585 & 85 & 84 & 82 & 77 & 71 & 56 \\
\hline Mavrilimumab $30 \mathrm{mg}$ & 818181 & 80 & 77 & 77 & 68 & 67 & 46 \\
\hline Placebo & 818181 & 79 & 79 & 73 & 47 & 38 & 30 \\
\hline
\end{tabular}

Figure 1 CONSORT diagram (A) and time to randomised study exit (B). Randomised study exit includes patients who withdrew from study treatment, patients who entered the OLE from week 12 as permitted in the protocol and those patients who entered the safety follow-up period at week 24. At week 12, $3(3.8 \%), 8(9.4 \%), 12(14.8 \%)$ and $37(45.7 \%)$ patients transferred to the OLE study because of lack of efficacy in the mavrilimumab 150, 100 and $30 \mathrm{mg}$ groups and placebo group, respectively. eow, every other week; OLE, open-label extension. 
Table 1 Patient demographics and baseline clinical characteristics

\begin{tabular}{|c|c|c|c|c|}
\hline & \multicolumn{3}{|l|}{ Mavrilimumab } & \multirow[b]{2}{*}{ Placebo $(n=81)$} \\
\hline & $150 \mathrm{mg}$ eow $(n=79)$ & $100 \mathrm{mg}$ eow $(n=85)$ & $30 \mathrm{mg}$ eow $(n=81)$ & \\
\hline \multicolumn{5}{|l|}{ Demographics } \\
\hline Female, $\mathrm{n}(\%)$ & $67(84.8)$ & $70(82.4)$ & $70(86.4)$ & $75(92.6)$ \\
\hline \multicolumn{5}{|l|}{ Race, n (\%) } \\
\hline White & 74 (93.7) & $81(95.3)$ & $76(93.8)$ & $76(93.8)$ \\
\hline Weight, kg, mean (SD) & $75.9(17.6)$ & $71.8(16.2)$ & $72.5(15.2)$ & $73.0(15.2)$ \\
\hline Body mass index, $\mathrm{kg} / \mathrm{m}^{2}$, mean (SD) & $28.4(6.2)$ & $26.3(5.3)$ & $27.3(5.1)$ & $27.5(5.1)$ \\
\hline \multicolumn{5}{|l|}{ Baseline clinical characteristics } \\
\hline Years since RA diagnosis, mean (SD) & $8.5(6.9)$ & $7.2(6.5)$ & $7.8(6.6)$ & $7.6(7.2)$ \\
\hline Rheumatoid factor-positive, n (\%) & $60(75.9)$ & $68(80.0)$ & $67(82.7)$ & $65(80.2)$ \\
\hline ACPA-positive, n (\%) & $61(77.2)$ & $63(74.1)$ & $66(81.5)$ & $59(72.8)$ \\
\hline Tender joint count, mean (SD) & $26.7(11.4)$ & $27.0(14.2)$ & $27.5(14.0)$ & $26.3(11.3)$ \\
\hline HAQ DI, mean (SD) & $1.58(0.53)$ & $1.58(0.52)$ & $1.52(0.62)$ & $1.63(0.48)$ \\
\hline CRP, mg/L, median (minimum-maximum) & $5.6(0.3-55.8)$ & $9.0(0.3-75.3)$ & $5.2(0.2-102.8)$ & $6.3(0.2-110.2)$ \\
\hline Normal, n (\%) & $27(34.2)$ & $22(25.9)$ & $32(39.5)$ & $24(29.6)$ \\
\hline Greater than ULN, $\mathrm{n}(\%)^{*}$ & $52(65.8)$ & $63(74.1)$ & $49(60.5)$ & $57(70.4)$ \\
\hline ESR, mm/hour, median (minimum-maximum) & $38.0(8-101)$ & $40.0(6-123)$ & $40.0(6-110)$ & $42.0(3-112)$ \\
\hline MBDA score, mean (SD) & $50.2(14.0)$ & $54.2(16.7)$ & $48.5(17.3)$ & $50.6(17.9)$ \\
\hline $\mathrm{C} 1 \mathrm{M}, \mathrm{ng} / \mathrm{mL}$, mean (SD) & $83.7(54.8)$ & $107.1(76.3)$ & $88.6(81.3)$ & $98.1(72.1)$ \\
\hline Methotrexate use, $n$ & 79 & $84 \dagger$ & 81 & 81 \\
\hline Dosage, mg/week, mean (SD) & $14.5(4.1)$ & $15.1(4.6)$ & $14.6(3.6)$ & $15.0(3.7)$ \\
\hline Prior biological therapy, $\mathrm{n}(\%)$ & $10(12.7)$ & $13(15.3)$ & $12(14.8)$ & $12(14.8)$ \\
\hline \multicolumn{5}{|l|}{ Reason for discontinuation, $\mathrm{n}(\%)$} \\
\hline Expense of medication & $2(2.5)$ & $2(2.4)$ & $1(1.2)$ & $1(1.2)$ \\
\hline Medication only in clinical trial & $7(8.9)$ & $9(10.6)$ & $8(9.9)$ & $8(9.9)$ \\
\hline Adverse event & $0(0.0)$ & $1(1.2)$ & $3(3.7)$ & $1(1.2)$ \\
\hline Other & $1(1.3)$ & $1(1.2)$ & $0(0.0)$ & $2(2.5)$ \\
\hline
\end{tabular}

\footnotetext{
${ }^{*}$ The upper limit of normal for CRP (high sensitivity) was $3 \mathrm{mg} / \mathrm{L}$.
}

tOne patient did not receive methotrexate (not identified until after randomisation), and this was considered a protocol violation.

ACPA, anticitrullinated protein antibody; CRP, C reactive protein; DAS28, Disease Activity Score 28; eow, every other week; ESR, erythrocyte sedimentation rate; HAQ DI, Health Assessment Questionnaire Disability Index; MBDA, multibiomarker disease activity; RA, rheumatoid arthritis; SD, standard deviation; ULN, upper limit of normal.

figure 4B). Significant decreases from baseline in C1M concentrations were also observed for patients receiving mavrilimumab 150 and $100 \mathrm{mg}$ eow compared with placebo from week 1 to week 24 ( $p<0.01$; figure $4 \mathrm{C})$.

\section{DISCUSSION}

This phase IIb study met its coprimary outcomes, with mavrilimumab treatment resulting in dosage-related, significantly greater reductions from baseline in DAS28-CRP scores at week 12 and a significantly greater percentage of ACR20 responders at week 24 , compared with placebo. The most effective dose was $150 \mathrm{mg}$ eow. Mavrilimumab-treated patients also demonstrated significantly greater improvements than those receiving placebo across a range of secondary and patient-reported outcomes $^{29}$ (see online supplementary table S4). The data presented here are consistent with and build on those presented previously for mavrilimumab $100 \mathrm{mg}$ by including a larger patient population, longer treatment duration and the higher $(150 \mathrm{mg})$ mavrilimumab dosage. ${ }^{19} 20$

A rapid and sustained clinical response to mavrilimumab 150 and $100 \mathrm{mg}$ eow was reflected in the reduction of CRP and ESR, concurrent decreases in MBDA score, a composite of soluble disease activity biomarkers and C1M concentration. ${ }^{27}$ A clear dosage-response relationship was observed for mavrilimumab-treated patients in most efficacy outcomes analysed and for biomarker analyses, but not in $\mathrm{AE}$ rates or other 
$A \sim$ Mavrilimumab $150 \mathrm{mg}$ eow $(\mathrm{n}=79)$

Mavrilimumab $100 \mathrm{mg}$ eow $(n=85)$

Mavrilimumab $30 \mathrm{mg}$ eow $(\mathrm{n}=81)$

Placebo $(n=81)$

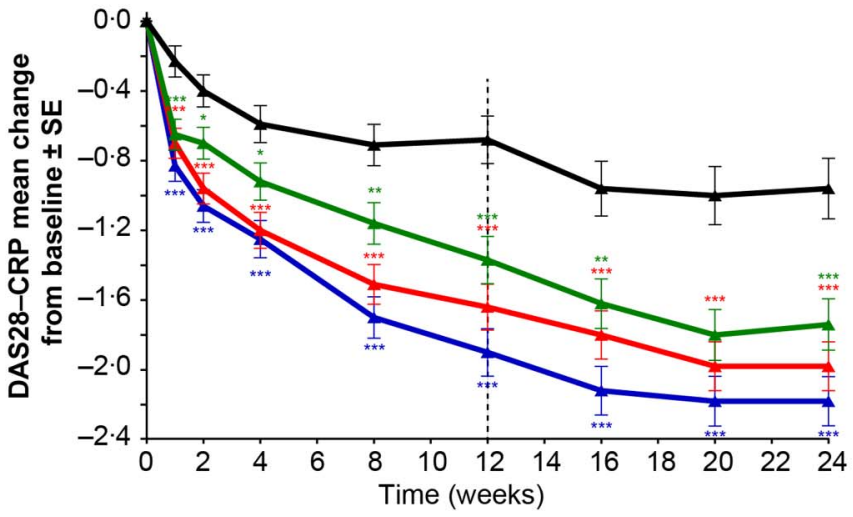

\begin{tabular}{|l|c|c|c|c|}
\hline & \multicolumn{3}{|c|}{ Mavrilimumab } & \\
\hline & $\begin{array}{c}150 \mathrm{mg} \text { eow } \\
(\mathrm{n}=79)\end{array}$ & $\begin{array}{c}100 \mathrm{mg} \text { eow } \\
(\mathrm{n}=85)\end{array}$ & $\begin{array}{c}30 \mathrm{mg} \text { eow } \\
(\mathrm{n}=81)\end{array}$ & $\begin{array}{c}\text { Placebo } \\
(\mathrm{n}=81)\end{array}$ \\
\hline Baseline mean & 5.67 & 5.91 & 5.73 & 5.78 \\
\hline $\begin{array}{l}\text { Adjusted mean change from } \\
\text { baseline at week 1 }\end{array}$ & -0.83 & -0.70 & -0.65 & -0.23 \\
\hline $\begin{array}{l}\text { Adjusted mean change from } \\
\text { baseline at week 12 }\end{array}$ & -1.90 & -1.64 & -1.37 & -0.68 \\
\hline $\begin{array}{l}\text { Adjusted mean change from } \\
\text { baseline at week 24 }\end{array}$ & -2.18 & -1.98 & -1.74 & -0.96 \\
\hline
\end{tabular}

B

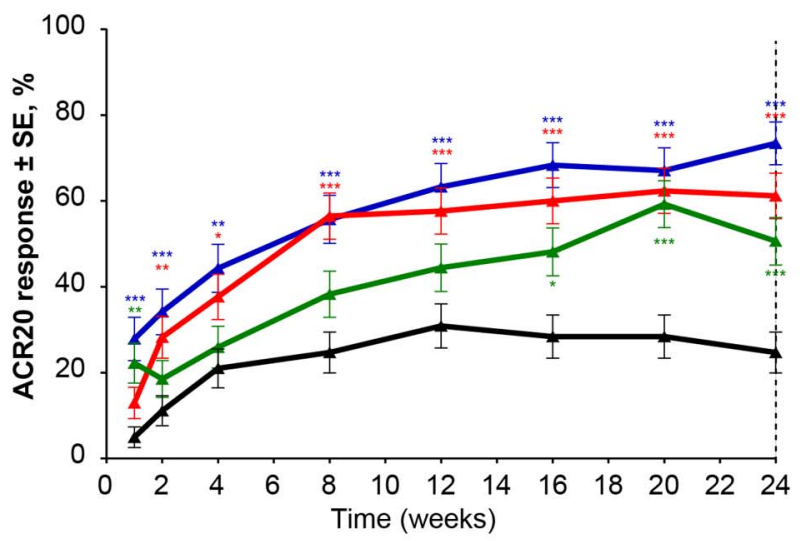

\begin{tabular}{|l|c|c|c|c|}
\hline & \multicolumn{3}{|c|}{ Mavrilimumab } & \\
\hline & $\begin{array}{c}150 \mathrm{mg} \text { eow } \\
(\mathrm{n}=79)\end{array}$ & $\begin{array}{c}100 \mathrm{mg} \text { eow } \\
(\mathrm{n}=85)\end{array}$ & $\begin{array}{c}30 \mathrm{mg} \text { eow } \\
(\mathrm{n}=81)\end{array}$ & $\begin{array}{c}\text { Placebo } \\
(\mathrm{n}=81)\end{array}$ \\
\hline ACR response at week 1, $\mathrm{n}(\%)$ & $22(27.8)$ & $11(12.9)$ & $18(22.2)$ & $4(4.9)$ \\
\hline ACR response at week 12, $\mathrm{n}(\%)$ & $50(63.3)$ & $49(57.6)$ & $36(44.4)$ & $25(30.9)$ \\
\hline ACR response at week 24, $\mathrm{n}(\%)$ & $58(73.4)$ & $52(61.2)$ & $41(50.6)$ & $20(24.7)$ \\
\hline
\end{tabular}

C

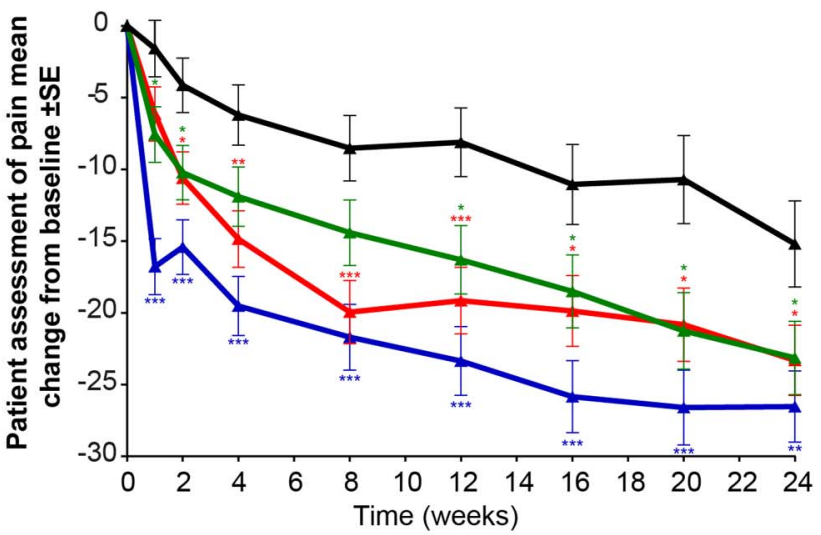

\begin{tabular}{|l|c|c|c|c|}
\hline & \multicolumn{3}{|c|}{ Mavrilimumab } & \\
\hline & $\begin{array}{c}150 \mathrm{mg} \text { eow } \\
(\mathrm{n}=79)\end{array}$ & $\begin{array}{c}100 \mathrm{mg} \text { eow } \\
(\mathrm{n}=85)\end{array}$ & $\begin{array}{c}30 \mathrm{mg} \text { eow } \\
(\mathrm{n}=81)\end{array}$ & $\begin{array}{c}\text { Placebo } \\
(\mathrm{n}=81)\end{array}$ \\
\hline Baseline mean & 62.35 & 63.58 & 62.65 & 62.16 \\
\hline $\begin{array}{l}\text { Adjusted mean change from } \\
\text { baseline at week 1 }\end{array}$ & -16.78 & -6.14 & -7.57 & -1.58 \\
\hline $\begin{array}{l}\text { Adjusted mean change from } \\
\text { baseline at week 12 }\end{array}$ & -23.35 & -19.15 & -16.30 & -8.11 \\
\hline $\begin{array}{l}\text { Adjusted mean change from } \\
\text { baseline at week 24 }\end{array}$ & -26.53 & -23.31 & -23.14 & -15.20 \\
\hline
\end{tabular}

Figure 2 Changes from baseline in DAS28-CRP score (A), ACR20 response (B) and changes from baseline in patient assessment of pain (C) by visit. ${ }^{*} p<0.05,{ }^{* *} p<0.01,{ }^{* *} p<0.001$ mavrilimumab versus placebo. ACR, American College of Rheumatology; DAS28-CRP, Disease Activity Score 28-C reactive protein; eow, every other week; SE, standard error.

safety parameters. However, as the study was powered specifically to assess the coprimary end points, the sample size and study duration were not sufficient to assess joint damage progression.

The number of patients who transferred to the OLE between weeks 12 and 24 because of lack of response was low in the mavrilimumab 150, 100 and $30 \mathrm{mg}$ eow groups compared with placebo (3 (3.8\%), 8 (9.4\%), $12(14.8 \%)$ and $37(45.7 \%)$, respectively). This could be seen as an indication of the benefit of mavrilimumab treatment; however, it is a limitation of the study analysis, as the response of these patients at week 24 , had they remained in the study, is unknown. To account for patients transferring to the OLE, a non-responder imputation for the ACR outcomes and a sensitivity analysis for DAS28-CRP were performed. The primary analysis method of MMRM resulted in a smaller difference from placebo than both the Last Observation Carried Forward (LOCF) and the Baseline Observation Carried Forward (BOCF) method (DAS28-CRP week 24 mavrilimumab $150 \mathrm{mg}$ eow difference from placebo: $\mathrm{MMRM}=-1.21 ; \mathrm{LOCF}=-1.46 ; \mathrm{BOCF}=-1.37$ ).

Mavrilimumab was generally well tolerated, with no substantial differences in AEs or SAEs between mavrilimumab-treated 
Mavrilimumab $150 \mathrm{mg}$ eow $(\mathrm{n}=79)$

A

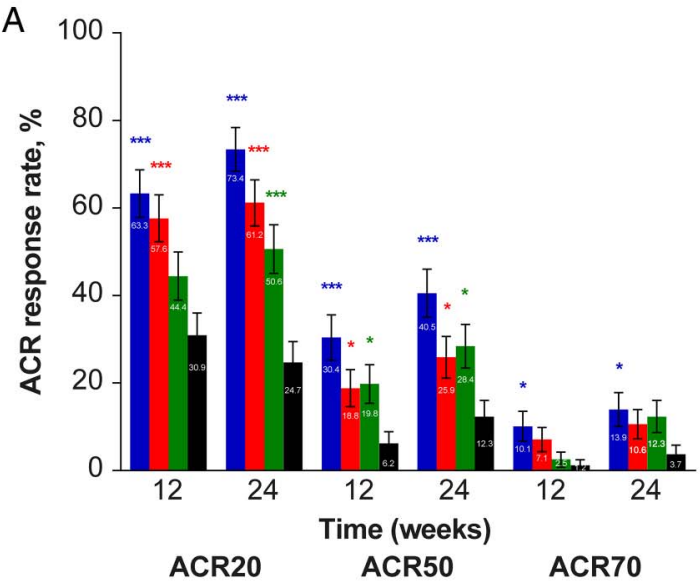

C

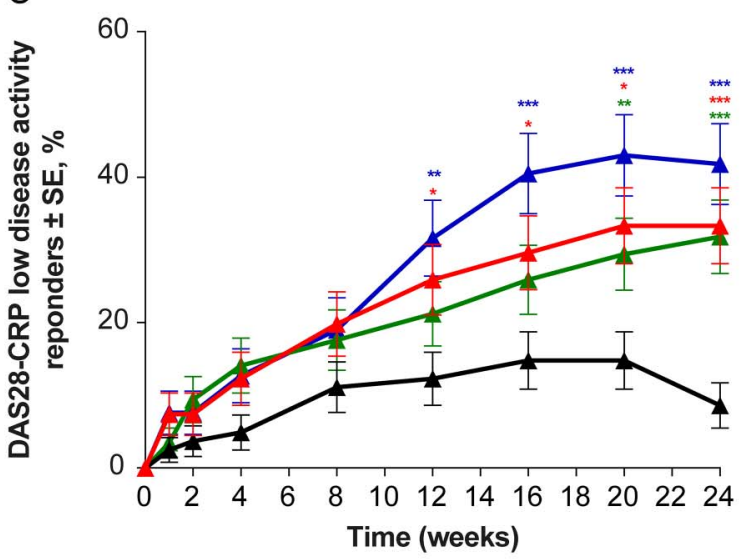

Mavrilimumab $30 \mathrm{mg}$ eow $(\mathrm{n}=81)$

Placebo $(n=81)$
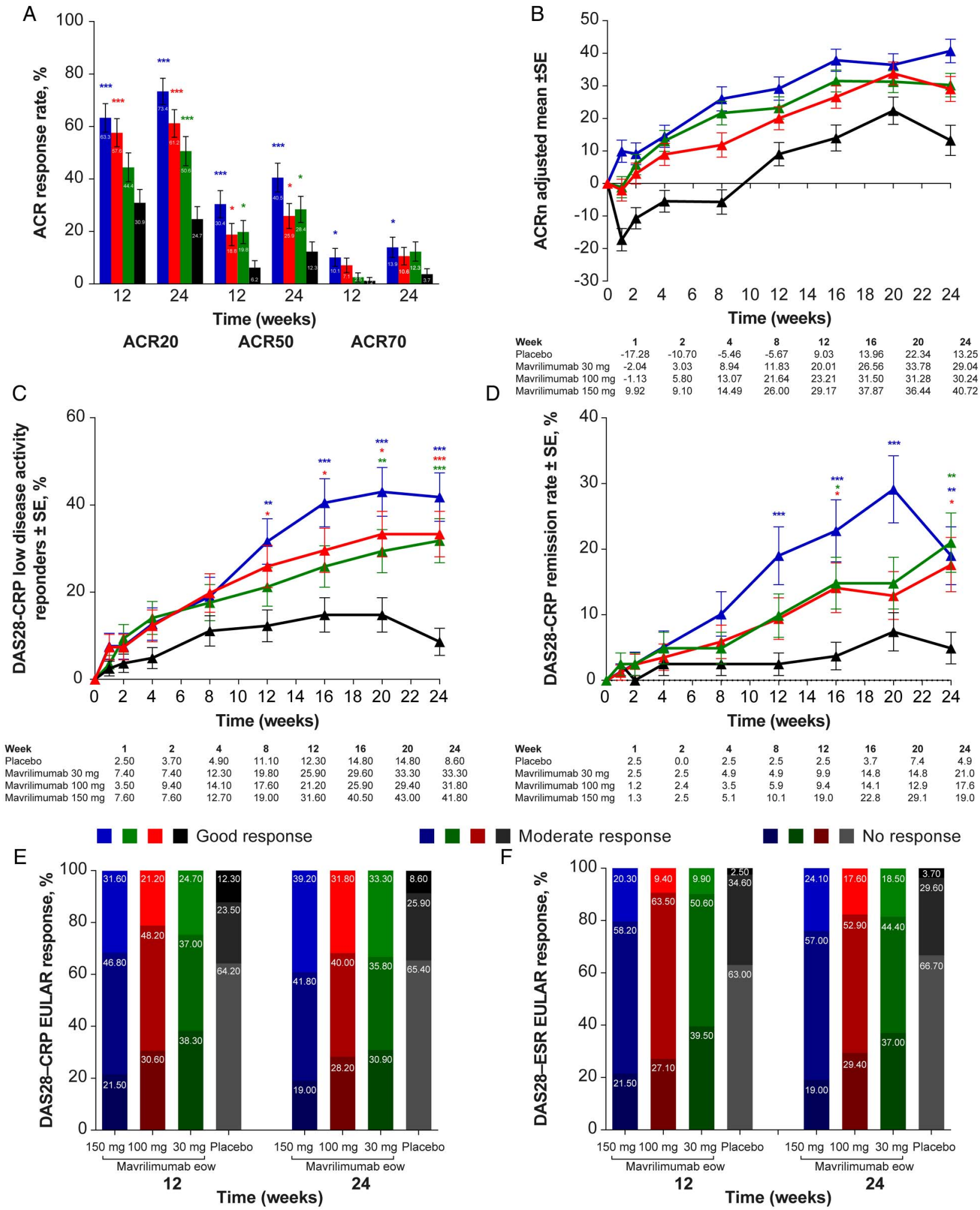

Figure 3 Analysis of secondary efficacy outcomes: ACR response rates (A), ACRn response over time (B), DAS28-CRP low disease activity responders (DAS28-CRP <3.2) (C), DAS28-CRP remission (DAS28-CRP <2.6) over time (D), DAS28-CRP European League Against Rheumatism (EULAR) response (E), DAS28-ESR EULAR response (F). ACR/EULAR response criteria are detailed in online supplementary table S6. DAS28-CRP remission defined as DAS28-CRP <2.6. DAS28-CRP low disease activity defined as DAS28-CRP <3.2. ACR, American College of Rheumatology; DAS28-CRP, Disease Activity Score 28-C reactive protein; ESR, erythrocyte sedimentation rate; eow, every other week; SE, standard error.

and placebo-treated patients (table 2). The percentage of patients experiencing TEAEs and TEAEs of special interest were similar in mavrilimumab versus placebo groups. The rate of serious infection was low (one serious pneumonia (mavrilimumab $30 \mathrm{mg}$ ) and one non-serious pneumonia (placebo)). Neutropenia was reported in three patients in the mavrilimumab $150 \mathrm{mg}$ 
A

Mavrilimumab $150 \mathrm{mg}$ eow $(n=79)$

Mavrilimumab $30 \mathrm{mg}$ eow $(\mathrm{n}=81)$

Mavrilimumab $100 \mathrm{mg}$ eow $(\mathrm{n}=85)$

Placebo $(n=81)$

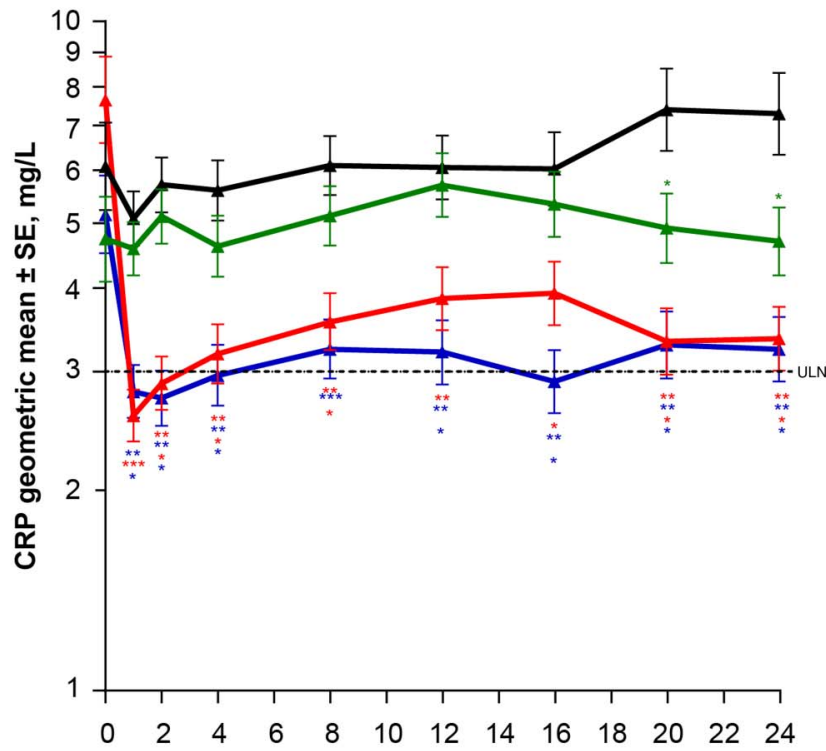

Time (weeks)

\begin{tabular}{|l|c|c|c|c|c|c|c|c|}
\hline Week & $\mathbf{1}$ & $\mathbf{2}$ & $\mathbf{4}$ & $\mathbf{8}$ & $\mathbf{1 2}$ & $\mathbf{1 6}$ & $\mathbf{2 0}$ & $\mathbf{2 4}$ \\
\hline Placebo & 5.080 & 5.710 & 5.600 & 6.100 & 6.060 & 6.030 & 7.390 & 7.290 \\
\hline Mavrilimumab $30 \mathrm{mg}$ & 4.580 & 5.120 & 4.620 & 5.130 & 5.700 & 5.340 & 4.920 & 4.700 \\
\hline Mavrilimumab $100 \mathrm{mg}$ & 2.580 & 2.880 & 3.190 & 3.560 & 3.860 & 3.930 & 3.330 & 3.360 \\
\hline Mavrilimumab $150 \mathrm{mg}$ & 2.800 & 2.740 & 2.960 & 3.240 & 3.210 & 2.900 & 3.290 & 3.240 \\
\hline
\end{tabular}

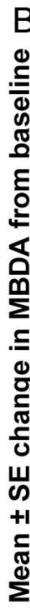
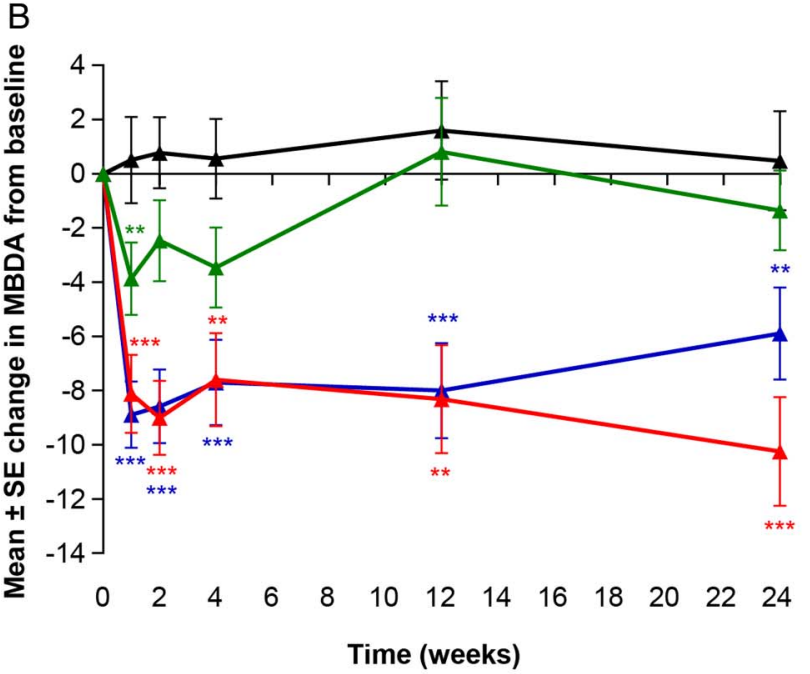

C

\begin{tabular}{|l|c|c|c|c|c|}
\hline Week & $\mathbf{1}$ & $\mathbf{2}$ & $\mathbf{4}$ & $\mathbf{1 2}$ & $\mathbf{2 4}$ \\
\hline Placebo & 0.508 & 0.775 & 0.559 & 1.600 & 0.479 \\
\hline Mavrilimumab $30 \mathrm{mg}$ & -3.868 & -2.466 & -3.456 & 0.811 & -1.350 \\
\hline Mavrilimumab $100 \mathrm{mg}$ & -8.120 & -9.000 & -7.596 & -8.314 & -10.245 \\
\hline Mavrilimumab $150 \mathrm{mg}$ & -8.885 & -8.578 & -7.596 & -8.000 & -5.890 \\
\hline
\end{tabular}

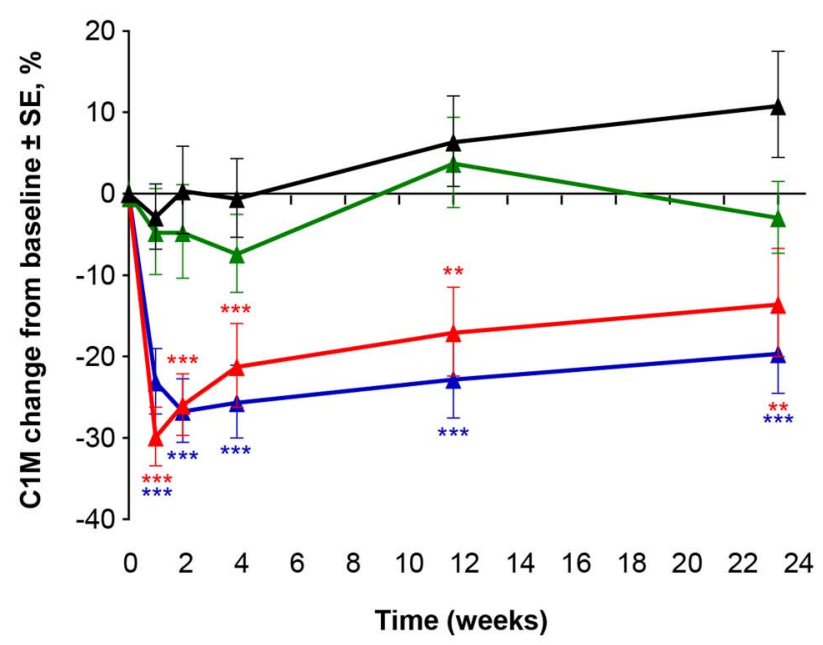

\begin{tabular}{|l|c|c|c|c|c|}
\hline Week & $\mathbf{1}$ & $\mathbf{2}$ & $\mathbf{4}$ & $\mathbf{1 2}$ & $\mathbf{2 4}$ \\
\hline Placebo & -2.888 & 0.309 & -0.626 & 6.312 & 10.793 \\
\hline Mavrilimumab $30 \mathrm{mg}$ & -4.801 & -4.805 & -7.443 & 3.706 & -2.984 \\
\hline Mavrilimumab $100 \mathrm{mg}$ & -29.931 & -26.003 & -21.258 & -17.115 & -13.601 \\
\hline Mavrilimumab $150 \mathrm{mg}$ & -23.150 & -26.747 & -25.672 & -22.824 & -19.669 \\
\hline
\end{tabular}

Figure 4 Adjusted geometric mean ratio to baseline in CRP concentrations (A), change from baseline in MBDA score (B) and C1M (C). * $p<0.05$, ${ }^{* *} p<0.01,{ }^{* *} p<0.001$ mavrilimumab versus placebo. For MBDA analyses (graph $A$ ), the number of patients for whom serum samples were analysed at each time point ranged from 57 to 64,53 to 60,53 to 61 and 40 to 59 for mavrilimumab 150, 100, 30 mg eow and placebo, respectively. For $\mathrm{C} 1 \mathrm{M}$ analyses (graph B), the number of patients for whom serum samples were analysed at each time point ranged from 73 to 76 , 74 to 84,62 to 78 and 54 to 77 for mavrilimumab 150, 100, 30 mg eow and placebo, respectively. CRP, C reactive protein; eow, every other week; MBDA, multibiomarker disease activity; SE, standard error; ULN, upper limit of normal. 
Table 2 Treatment-emergent adverse events occurring in $\geq 3 \%$ of patients in any group and all serious adverse events

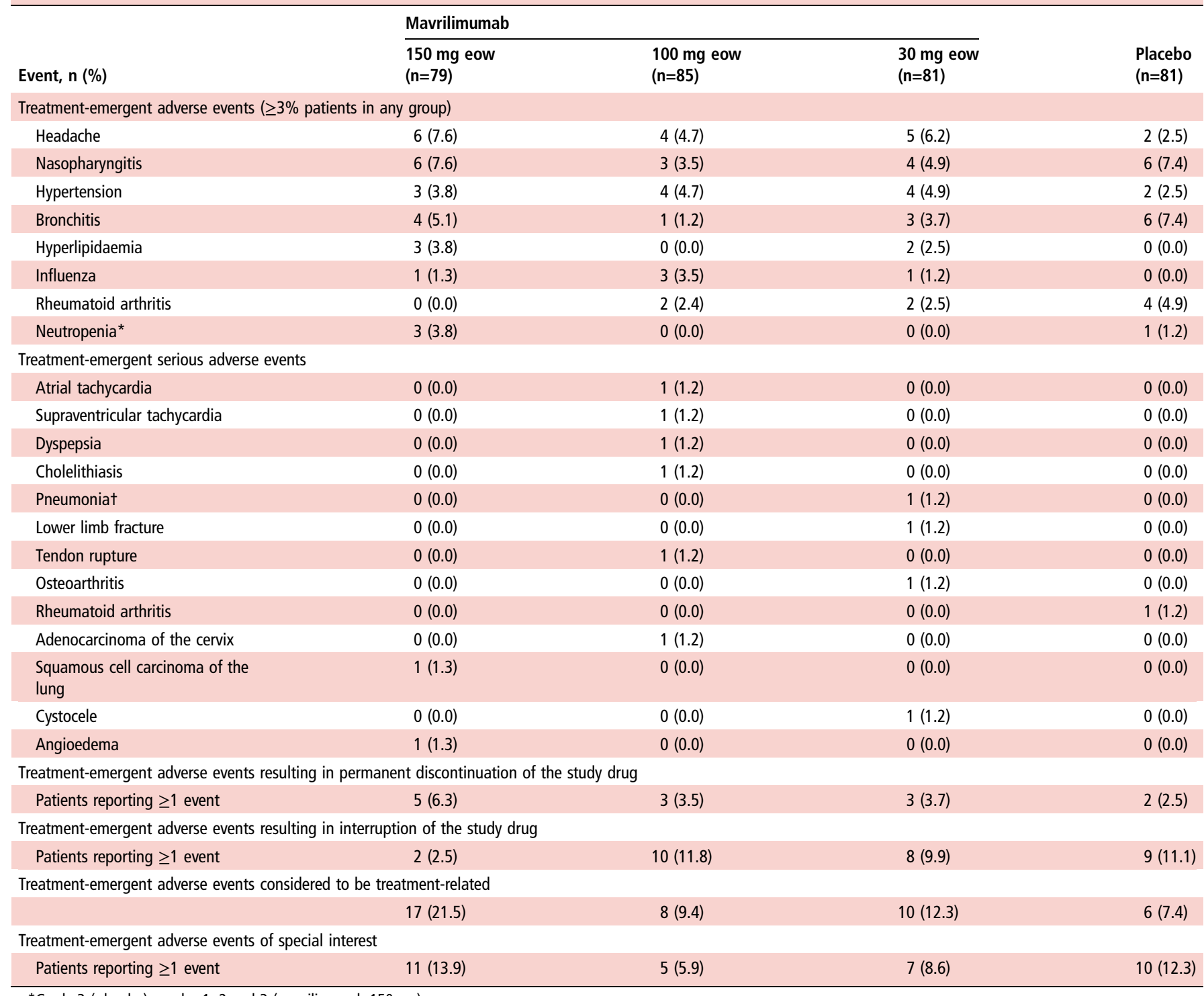

*Grade 3 (placebo); grades 1, 2 and 3 (mavrilimumab $150 \mathrm{mg}$ ).

tOne non-serious pneumonia was reported in the placebo group.

eow, every other week.

group (grades 1, 2 and 3) and one patient in the placebo group (grade 3). ADAs were detected more frequently in patients treated with lower mavrilimumab dosages and none at the $150 \mathrm{mg}$ dosage, consistent with the previous observations that development of ADAs is inversely associated with dose. ${ }^{30} 31$ The safety profile for mavrilimumab observed in this study was similar to that reported in previous mavrilimumab studies ${ }^{17} 19$ and emerging data with other GM-CSF pathway inhibitors. ${ }^{32}$

No substantial increase in pulmonary events, or apparent dosage-response changes in pulmonary function, dyspnoea score or oxygen saturation, was noted for mavrilimumab-treated patients compared with those receiving placebo. Furthermore, mavrilimumab treatment was not associated with any confirmed or suspected case of PAP, as verified by an Independent Pulmonary Expert Committee. An open-label, phase II safety study (NCT01712399) aims to establish the long-term safety and efficacy profile of mavrilimumab $100 \mathrm{mg}$ in patients with RA.

Despite the success of the currently available biologics in RA, a considerable percentage of patients do not achieve long-term responses to these therapies. ${ }^{33}$ Consequently, new treatments employing different mechanisms of action from those currently available, such as GM-CSFR antagonism, are needed. Data from this study demonstrate that mavrilimumab, particularly at a dosage of $150 \mathrm{mg}$ eow, provides a rapid, effective and welltolerated potential treatment for patients with RA. Moreover, blockade of GM-CSF signalling could be applicable to patients for whom treatment with biologics targeting other pathways has failed or to those with other inflammatory/autoimmune diseases. ${ }^{33}$ This proof-of-concept study confirms that inhibition of GM-CSF activity is a promising and novel therapeutic approach for patients with RA, including those who do not adequately respond to currently available therapies.

\section{Author affiliations}

${ }^{1}$ Department of Rheumatology and Clinical Immunology, Charité-University Medicine Berlin, Free University, and Humboldt University Berlin, Berlin, Germany ${ }^{2}$ Institute of Infection Immunity and Inflammation, University of Glasgow, Glasgow, UK

${ }^{3}$ Center for Rheumatology, Albany Medical College, Albany, New York, USA

${ }^{4}$ Universidad de Chile and Hospital San Juan de Dios, Santiago, Chile

${ }^{5}$ Division of Rheumatology, Department of Internal Medicine and Gerontology, Jagiellonian University Medical College, Krakow, Poland 
${ }^{6}$ Institute of Rheumatology, Charles University, Prague, Czech Republic

${ }^{7}$ Department of Internal Medicine, University of Cologne, Cologne, Germany

${ }^{8}$ Organizacion Medica de Investigación, Buenos Aires, Argentina

${ }^{9}$ Medlmmune, Cambridge, UK

${ }^{10}$ Medlmmune, Gaithersburg, Maryland, USA

${ }^{11}$ Medlmmune, Mountain View, California, USA

${ }^{12}$ Division of Rheumatology, Immunology and Allergy, Brigham and Women's Hospital, Boston, Massachusetts, USA

Correction notice This article has been corrected since it published Online First. Figure $3 \mathrm{~A}$ has been updated.

Acknowledgements The authors would like to thank Crescendo Biosciences, Inc. and Nordic Bioscience for the MBDA and C1M analyses, respectively. The authors would also like to thank the study investigators, patients and the AstraZeneca/ Medlmmune study group. The study was funded by AstraZeneca/Medlmmune. Editorial assistance was provided in the development and revision of the manuscript by Michael A Nissen, ELS, of AstraZeneca. Marius Albulescu, MD, of Medlmmune, contributed to study design, analysis and interpretation of data. Medical writing support was provided by Niki Panagiotaki, PhD and Katie Alexander, PhD, QXV Comms (an Ashfield business, part of UDG Healthcare plc), Macclesfield, UK, which was fully funded by Medlmmune. Matthew A Sleeman is a former employee of Medlmmune; his current affiliation is Regeneron Pharmaceuticals, Inc., Tarrytown, NY

Contributors GRB contributed to the study design, interpretation and generation of data, manuscript preparation and review; IBM contributed to study design, interpretation, manuscript preparation and review; JK contributed to study design, data analysis and interpretation, and manuscript preparation and review; PM contributed to data collection, review and interpretation; MK contributed to data collection and manuscript review; JV contributed to study design, data collection, analysis and interpretation, and manuscript preparation and review; AR-R contributed to study design, interpretation of data, manuscript preparation and review; EM contributed to protocol assessment, data analysis and interpretation, and manuscript preparation and review; MAS contributed to study design, data analysis and interpretation and manuscript preparation and review; AG contributed to study design and set-up, data cleaning, analysis and interpretation, and manuscript preparation and review; DS contributed to study design, data cleaning, analysis and interpretation, and manuscript preparation and review; XG contributed to data collection, analysis and interpretation, and manuscript preparation and review; WIW contributed to study design, data analysis and interpretation, and manuscript preparation and review; BW contributed to study design, data analysis and interpretation, and manuscript preparation and review; C-YW contributed to study design, data collection, and manuscript preparation and review; PCR contributed to study design, data collection, analysis and interpretation, and manuscript preparation and review; DC contributed to study design and conduct, data analysis and interpretation, and manuscript preparation and review; MEW contributed to study design and set-up, data analysis and interpretation, and manuscript preparation and review.

Funding The study was funded by AstraZeneca/Medlmmune.

Competing interests GRB is a consultant and has received lecture fees from Abbvie, Bristol-Myers Squibb, MSD, Pfizer, Roche, UCB; IM has received grants and personal fees from Abbvie, AstraZeneca, Bristol-Myers Squibb, Janssen, Medlmmune, MSD, Pfizer, UCB; JK is a shareholder and employee of Corrona; has received grants from Abbvie, Amgen, Genentech, Lilly, Pfizer; and is a consultant for Abbvie, Amgen Genentech, Lilly, Pfizer, BMS and Medlmmune; PM has received grants from Medlmmune; JV is a consultant for Biotest and Samsung Bioepics and has participated in speaker bureaus for Abbvie, MSD, Pfizer, UCB, Roche; AR-R received honoraria for consultation and lectures from Abbvie, Amgen, Chugai, Roche, UCB, MSD, Pfizer, Lilly, Sanofi, Novartis, BMS; EM has received a grant from Organizicion medica de Investigacion; MAS was formerly a full-time employee of Medlmmune, a wholly owned subsidiary of AstraZeneca; AG, DS, XG, WIW, BW, C-YW, PCR and $D C$ are employees of Medlmmune and hold AstraZeneca shares; MEW has received research grants from Bristol-Myers Squibb, Crescendo Bioscience and UCB, and is a consultant for Abbvie, Amgen, AstraZeneca, Bristol-Myers Squibb, Corrona, Crescendo Bioscience, Genentech/Roche, Janssen, Lycera, Lilly, Medlmmune, Merck, Pfizer, Regeneron, Sanofi, UCB.

Ethics approval Institutional Review Board/Independent Ethics Committee.

Provenance and peer review Not commissioned; externally peer reviewed.

Open Access This is an Open Access article distributed in accordance with the Creative Commons Attribution Non Commercial (CC BY-NC 4.0) license, which permits others to distribute, remix, adapt, build upon this work non-commercially, and license their derivative works on different terms, provided the original work is properly cited and the use is non-commercial. See: http://creativecommons.org/ licenses/by-nc/4.0/

\section{REFERENCES}

1 Harrold L, Palmer JL, Curtis JR, et al. Trends over time in achievement of low disease activity among biologic initiators with rheumatoid arthritis. Arthritis Rheumatol 2015;67(Suppl 10). http://acrabstracts.org/abstract/trends-over-time-inachievement-of-low-disease-activity-among-biologic-initiators-with-rheumatoidarthritis/

2 Furst $D E$, Pangan AL, Harrold LR, et al. Greater likelihood of remission in rheumatoid arthritis patients treated earlier in the disease course: results from the Consortium of Rheumatology Researchers of North America registry. Arthritis Care Res (Hoboken) 2011;63:856-64.

3 Wicks IP, Roberts AW. Targeting GM-CSF in inflammatory diseases. Nat Rev Rheumatol 2016;12:37-48.

4 Di Franco M, Gerardi MC, Lucchino B, et al. Mavrilimumab: an evidence based review of its potential in the treatment of rheumatoid arthritis. Core Evid 2014;9:41-8.

5 McInnes IB, Schett G. The pathogenesis of rheumatoid arthritis. N Engl J Med 2011:365:2205-19.

6 Mulherin D, Fitzgerald O, Bresnihan B. Synovial tissue macrophage populations and articular damage in rheumatoid arthritis. Arthritis Rheum 1996;39:115-24.

7 Herndler-Brandstetter D, Flavell RA. Producing GM-CSF: a unique T helper subset? Cell Res 2014;24:1379-80.

8 Bell AL, Magill MK, McKane WR, et al. Measurement of colony-stimulating factors in synovial fluid: potential clinical value. Rheumatol Int 1995;14: 177-82.

9 Fiehn C, Wermann M, Pezzutto A, et al. [Plasma GM-CSF concentrations in rheumatoid arthritis, systemic lupus erythematosus and spondyloarthropathy]. Z Rheumatol 1992:51:121-6.

10 Greven DE, Cohen ES, Gerlag DM, et al. Preclinical characterisation of the GM-CSF receptor as a therapeutic target in rheumatoid arthritis. Ann Rheum Dis 2015;74: 1924-30

11 Pereira J, Velloso ED, Loterio $\mathrm{HA}$, et al. Long-term remission of neutropenia in Felty's syndrome after a short GM-CSF treatment. Acta Haematol 1994:92:154-6.

12 Cook AD, Turner AL, Braine EL, et al. Regulation of systemic and local myeloid cell subpopulations by bone marrow cell-derived granulocyte-macrophage colony-stimulating factor in experimental inflammatory arthritis. Arthritis Rheum 2011;63:2340-51.

13 Cook AD, Pobjoy J, Sarros S, et al. Granulocyte-macrophage colony-stimulating factor is a key mediator in inflammatory and arthritic pain. Ann Rheum Dis 2013;72:265-70.

14 Hamilton JA. Colony-stimulating factors in inflammation and autoimmunity. Nat Rev Immunol 2008:8:533-44.

15 Trapnell BC, Carey BC, Uchida K, et al. Pulmonary alveolar proteinosis, a primary immunodeficiency of impaired GM-CSF stimulation of macrophages. Curr Opin Immunol 2009;21:514-21.

16 Minter RR, Cohen ES, Wang B, et al. Protein engineering and preclinical development of a GM-CSF receptor antibody for the treatment of rheumatoid arthritis. Br J Pharmacol 2013;168:200-11.

17 Burmester GR, Feist E, Sleeman MA, et al. Mavrilimumab, a human monoclona antibody targeting GM-CSF receptor- $\alpha$, in subjects with rheumatoid arthritis: a randomised, double-blind, placebo-controlled, phase I, first-in-human study. Ann Rheum Dis 2011;70:1542-9.

18 Wang B, Lau YY, Liang M, et al. Mechanistic modeling of antigen sink effect for mavrilimumab following intravenous administration in patients with rheumatoid arthritis. J Clin Pharmacol 2012:52:1150-61.

19 Burmester GR, Weinblatt ME, Mclnnes IB, et al. Efficacy and safety of mavrilimumab in subjects with rheumatoid arthritis. Ann Rheum Dis 2013;72:1445-52.

20 Takeuchi T, Tanaka Y, Close D, et al. Efficacy and safety of mavrilimumab in Japanese subjects with rheumatoid arthritis: Findings from a Phase lla study. Mod Rheumatol 2015;25:21-30.

21 Ryan PC, Sleeman MA, Rebelatto M, et al. Nonclinical safety of mavrilimumab, an anti-GMCSF receptor alpha monoclonal antibody, in cynomolgus monkeys: relevance for human safety. Toxicol Appl Pharmacol 2014;279:230-9.

22 Burmester $G$, Michaels $M$, Close $D$, et al. Results of a comprehensive review of pulmonary function and safety data in a phase IIb clinical program testing anti-GM-CSF receptor antagonist mavrilimumab for treatment of RA. Arthritis Rheum 2016;68(Suppl 10):3581-4.

23 Aletaha D, Neogi T, Silman AJ, et al. 2010 Rheumatoid arthritis classification criteria: an American College of Rheumatology/European league against rheumatism collaborative initiative. Arthritis Rheum 2010;62:2569-81.

24 van Gestel AM, Haagsma CJ, van Riel PL. Validation of rheumatoid arthritis improvement criteria that include simplified joint counts. Arthritis Rheum 1998:41:1845-50. 


\section{Clinical and epidemiological research}

25 Curtis JR, van der Helm-van Mil AH, Knevel R, et al. Validation of a novel multibiomarker test to assess rheumatoid arthritis disease activity. Arthritis Care Res (Hoboken) 2012;64:1794-803.

26 Leeming DJ, He Y, Veidal S, et al. A novel marker for assessment of liver matrix remodeling: an enzyme-linked immunosorbent assay (ELISA) detecting a MMP generated type I collagen neo-epitope (C1M). Biomarkers 2011;16:616-28.

27 Siebuhr AS, Bay-Jensen AC, Leeming DJ, et al. Serological identification of fast progressors of structural damage with rheumatoid arthritis. Arthritis Res Ther 2013;15:R86.

28 Ge M, Durham LK, Meyer RD, et al. Covariate-adjusted difference in proportions from clinical trials using logistic regression and weighted risk differences. Drug Inf J 2011;45:481-93.

29 Kremer J, Burmester G, Weinblatt M, et al. Analysis of patient-reported outcomes during treatment with mavrilimumab, a human monoclonal antibody targeting GM-CSFRá, in the randomized phase 2b EARTH EXPLORER 1 study. Abstract presented at the American College of Rheumatology (ACR) annual meeting; 2014. http://acrabstracts org/abstracts/analysis-of-patient-reported-outcomes-during- treatment-with-mavrilimumab-a-human-monoclonal-antibody-targeting-gmcsfra-in-the-randomized-phase-2b-earth-explorer-1-study/2014 http:// acrabstracts.org/abstracts/analysis-of-patient-reported-outcomes-duringtreatment-with-mavrilimumab-a-human-monoclonal-antibody-targeting-gmcsfra-in-the-randomized-phase-2b-earth-explorer-1-study/ (accessed 11 Jun 2014).

30 Jullien D, Prinz JC, Nestle FO. Immunogenicity of biotherapy used in psoriasis: the science behind the scenes. J Invest Dermatol 2015;135:31-8.

31 van Schouwenburg PA, Rispens T, Wolbink GJ. Immunogenicity of anti-TNF biologic therapies for rheumatoid arthritis. Nat Rev Rheumatol 2013;9:164-72.

32 Behrens F, Tak PP, Østergaard M, et al. MOR103, a human monoclonal antibody to granulocyte-macrophage colony-stimulating factor, in the treatment of patients with moderate rheumatoid arthritis: results of a phase $\mathrm{lb} / \mathrm{lla}$ randomised, double-blind, placebo-controlled, dose-escalation trial. Ann Rheum Dis 2015;74:1058-64.

33 Burmester GR, Feist E, Dörner T. Emerging cell and cytokine targets in rheumatoid arthritis. Nat Rev Rheumatol 2014;10:77-88. 